\title{
Avaliação do Desenvolvimento de Embriōes Bovinos Pós-Biópsia: um Modelo para Treinamento
}

\author{
Evaluation of the Post-Biopsy Development of Bovine Embryos: Proposal of a Training Model
}

Carlos Gilberto Almodin, Antonio Fernandes Moron, Luiz Kulay Junior

Edegar Krüger, Lis Andréa Cardoso Pereira, Vania Cibele Minguetti-Câmara

\section{RESLMO}

Objetivo: montar um protocolo animal para estudo e treinamento em biópsia embrionária. Métodos: ovários de vaca obtidos em abatedouro eram transportados ao laboratório onde os oócitos aspirados eram maturados. Posteriormente eram submetidos à fertilização in vitro. No dia 5 pós-fertilização, os embriões eram biopsiados, com a abertura da zona pelúcida realizada mediante lâmina de corte ajustada ao microscópio óptico. Após abertura da zona pelúcida 1 ou 2 blastômeros eram removidos dos embriões. Após a biópsia, os embriões permaneciam em co-cultivo por mais três dias. Ao final deste tempo, o desenvolvimento dos embriões era avaliado e comparado ao do grupo controle por meio de estudo morfológico e contagem do número de células, usando coloração específica para núcleos.

Resultados: dos 57 embriões biopsiados, 40 atingiram o estágio de blastocisto (70,2\%) e em 11 foi observado o "hatching" (27,5\%). No grupo controle obtiveram-se 42 blastocistos $(73,7 \%)$ e, destes, 11 chegaram a "hatching" (26,2\%). Após contagem do número de células, observouse que não houve diferença estatisticamente significante entre os 2 grupos.

Conclusão: podemos verificar por meio dos resultados que o protocolo proposto foi tecnicamente viável, além de fornecer bom número de embriões, pela facilidade de obtenção de oócitos bovinos, podendo ser adotado para treinamento.

PALAVRAS-CHAVE: Infertilidade. Cultura de tecidos. Fertilização in vitro. Modelos experimentais.

\section{Introdução}

O recente avanço dos métodos de diagnóstico pré-natal, já dominados e rotineiros em muitos centros, conquistou seu espaço na prática médica diária, justificado pela incidência de 2,0 a 13,6\% de malformações congênitas nos recém-nascidos ${ }^{1}$.

Após longo período de pesquisas, nasceu a ciência da citogenética humana na década de 50, quando cientistas criaram técnicas eficazes para análise dos cromossomos. A princípio, estudos demonstraram sucesso com cultura de linfócitos obtidos de sangue periférico e de fibroblastos originários de biópsia de pele. Em 1966, Steele e Breg $^{2}$ demostraram a possibilidade de se

Materbaby - Reprodução Humana e Genética, Maringá - PR Correspodência:

Carlos Gilberto Almodin

Av. XV de Novembro, 1232

87013-230 - Maringá - PR determinar a constituição cromossômica de um feto pela análise de células cultivadas do líquido amniótico, sendo a trissomia do 21 , a primeira anomalia diagnosticada pela cultura de células provenientes de amniocentese, relatada por Valenti et al. ${ }^{3}$.

$\mathrm{Na}$ procura de tornar o diagnóstico mais precoce, ocorreu a partir dos anos 80 o domínio das técnicas de colheita de vilo corial, testes bioquímicos tais como a-fetoproteína, estriol e beta HCG, além da antecipação da colheita do líquido amniótico para a $16^{\underline{a}}$ semana. Os testes bioquímicos, aliados à melhoria das técnicas de bandeamento, já propiciam diagnósticos seguros e que nos orientam na condução de uma gestação já a partir da $10^{\underline{a}}$ semana.

Em 1991, Verlinsky e Kuliev ${ }^{4}$, durante o "First International Symposium on Preimplantation Genetics”, relataram as técnicas para detecção de várias doenças genéticas antes da implantação, 
podendo ser aplicadas aos embriões obtidos em fertilização in vitro. Ao diagnóstico pré-natal veio somar-se o diagnóstico pré-implantação, oferecendo a oportunidade de obtermos o diagnóstico antes da efetivação da interação embrião-útero, permitindo a seleção embrionária e evitando assim o abortamento seletivo nos casos de anormalidade ${ }^{4}$.

Os primeiros estudos em biópsia de embriões com finalidade de diagnóstico pré-implantação foram realizados em coelhos por Gardner e Edwards em $1968^{5}$. Eles removeram células do trofectoderma com a finalidade de determinar o sexo dos mesmos e confirmaram seus resultados transferindo os blastocistos para as mães e verificando o nascimento dos coelhos.

Estudos em mamíferos como macacos ${ }^{6} \mathrm{e}$ camundongos $^{7,8}$ demonstraram a possibilidade de desenvolvimento dos embriões após a biópsia, e também que este sucesso depende do estágio celular em que é realizada a biópsia, do número de células removidas e da técnica de biópsia utilizada. A biópsia em embriões humanos pode ser realizada quando o embrião alcança o estágio de 3 células, mas é preferivel biopsiar em estágios mais tardios (antes da compactação), quando a perda de um ou dois blastômeros não causa redução no número de células ${ }^{9}$. Hardy et al. ${ }^{10}$ verificaram que a biópsia em embriões de 6-10 células não causa efeito adverso sobre o metabolismo, sobre o número de embriões que chegam ao estágio de blastocistos e sobre a massa celular interna do trofectoderma.

Já existe um consenso quanto ao estágio ideal para biópsia em cada espécie animal e o número ideal de células a serem removidas. No entanto, existem controvérsias ainda quanto a melhor técnica a ser utilizada, talvez devido ao fato que todas necessitam de treinamento. Nosso trabalho destinou-se à padronização de um protocolo aplicável em animais para aprimoramento técnico do pessoal envolvido no procedimento de biópsia, com avaliação por meio do desenvolvimento de embriões bovinos pós-biópsia, possibilitando a aquisição de experiência e treinamento.

\section{Material e Métodos}

A fertilização in vitro foi realizada seguindo modificação da técnica de Pavlock ${ }^{11}$, sendo os ovários de vacas obtidos em abatedouro local sem critério de escolha. No laboratório, os folículos eram aspirados e o líquido folicular era examinado sob microscópio estereoscópico para identificação dos oócitos. Após identificação, os oócitos eram lavados em solução salina tamponada (D-PBS; GIBCO
Laboratories, Grand Island, NY, USA) e transferidos para meio 199 (Sigma M-2154, Sigma Chemical Co., St Louis, MO, USA), suplementado com lactato de cálcio $\left(5,5 \mathrm{mmol} \mathrm{l}^{-1}\right)$, piruvato de sódio $(2,3 \mathrm{mmol}$ $\left.\mathrm{1}^{-1}\right)$, bicarbonato de sódio $\left(9,5 \mathrm{mmol}^{-1}\right)$, $\operatorname{HEPES}(5,9$ mmol $\left.\mathrm{l}^{-1}\right)$, L-glutamina $\left(0,7 \mathrm{mmol}^{-1}\right)$, estreptomicina (15,6 $\mathrm{mg}^{-\mathrm{ml}^{-1}}$ ), penicilina $\left(7,5 \mathrm{mg} \cdot \mathrm{ml}^{-1}\right)$ (Sigma), FSH $\left(10 \mu \mathrm{g} \mathrm{ml}^{-1}\right)$ e $20 \%$ de soro de vaca no cio. Os oócitos permaneciam em incubadora (Forma modelo 3159) para maturação por um período de 24 a 26 horas.

O sêmen para fertilização era escolhido aleatoriamente, sem preferência por raça (Central de Sêmen Lagoa da Serra, Londrina, PR). A avaliação da concentração e da motilidade iniciais eram realizadas e somente amostras que apresentassem mais de $10 \times 10^{6}$ espermatozóides móveis $/ \mathrm{ml}$ eram utilizadas nos experimentos. $\mathrm{O}$ "swim up" para ativação e capacitação dos espermatozóides foi realizado de acordo com Parrish et al. ${ }^{12}$ utilizando meio TALP, suplementado com BSA (6 $\left.\mathrm{mg} \mathrm{ml}^{-1}\right)$ e piruvato de sódio ( $1 \mathrm{mmol}$ $\left.\mathrm{ml}^{-1}\right)$. Aproximadamente $1 \times 10^{6}$ espermatozóides eram adicionados às placas contendo os oócitos, previamente transferidos para o meio de fecundação preparado segundo Bavister e Yanagimack et al. ${ }^{13}$.

Entre 18 a 24 horas após a fertilização, os prováveis pré-embriões eram transferidos para placas com células Vero (células de cápsula renal de macacos Rhesus). No 5º dia pós-fertilização os embriões eram observados sob microscópio invertido (Olimpus CK2) para determinação da porcentagem de desenvolvimento embrionário. Apenas embriões que ultrapassavam o estágio de oito células eram separados para aspiração dos blastômeros. Para o grupo controle também eram selecionados apenas embriões com mais de oito células. Os embriões eram selecionados indistintamente para a biópsia ou para o grupo controle. Os embriões biopsiados e aqueles destinados ao grupo controle eram mantidos em co-cultura separadamente, sendo avaliados no $7^{\circ}$ e $8^{\circ}$ dias pós-fertilização.

Antes das biópsias, procedia-se à abertura da zona pelúcida mecanicamente, mediante um micromanipulador, esquematizado e confeccionado para este estudo, utilizando-se um compasso ajustado à objetiva do microscópio. Na outra extremidade do compasso era colocada uma pequena garra que segura a lâmina cortante. Este equipamento era adaptado a um microscópio óptico comum (Olympus) e com o auxílio da platina o embrião que se encontrava em lâminas de vidro, previamente preparadas com gotas de $50 \mu \mathrm{l}$ de PBS, alcançava a lâmina cortante. Deste modo podiase realizar uma pequena abertura na zona pelúcida do embrião. 
Logo após, os embriões eram transferidos para placas de Petri (Nunclon, Denmark), contendo microgotas de PBS, cobertas com óleo mineral (Sigma). Sob microscópio invertido Diaphot Nikon (Nikon, Tokyo, Japan), com contraste de fase Hoffman, a aspiração dos blastômeros era realizada tão logo a abertura realizada fosse identificada e posicionada às 3 horas. Com o auxílio de micropipetas (Humagem, Virginia, USA) adaptadas a micromanipuladores MMO-204D e injetores IM6 (Narishige Co., Tokyo, Japan) a micromanipulação era finalizada com a aspiração de um a dois blastômeros (Figuras 1 e 2). Findo o procedimento, os embriões eram lavados quatro a sete vezes em PBS e mantidos em co-cultura por mais 3 dias. $\mathrm{O}$ número de células, a compactação, estreitamento da zona pelúcida, formação da cavidade blastocélica e o fenômeno de extrusão da zona pelúcida pelo blastocisto ("hatching") eram observados ao microscópio invertido durante o período de 3 dias, até que, decorrido este tempo, o número de células era contado por meio de técnicas de coloração.

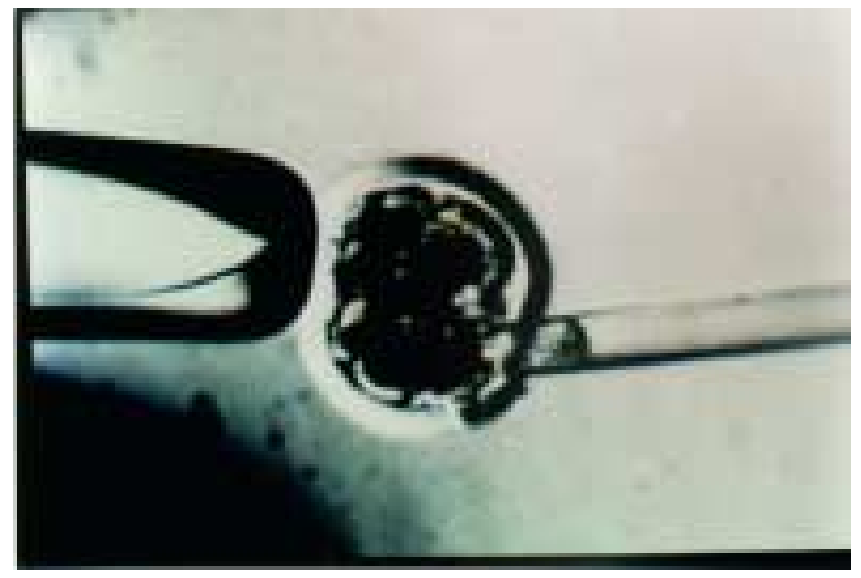

Figura 1 - Biópsia de embrião bovino em estágio de mórula

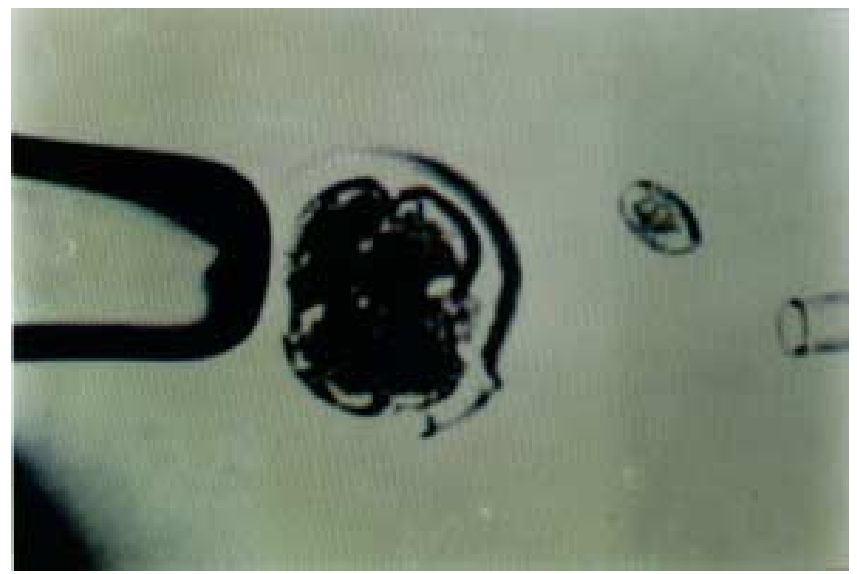

Figura 2 - Embrião biopsiado
A técnica de coloração utilizada foi descrita por Papaioannoou e Ebert em $1988^{14}$, com adaptação da técnica de coloração dupla para diferenciar células ICM (“Inner Cells Mass") e trofoblásticas. Os embriões (mórulas e blastocistos) eram lavados em PBS e transferidos para solução ácida de Tyrode (Sigma T1788) até a quase total dissolução da zona pelúcida. Os embriões eram então lavados rapidamente em PBS a $-4^{\circ} \mathrm{C}$ e em seguida eram transferidos para solução de Hoescht 33342 (Sigma, B2261), 0, 1 $\mu \mathrm{g} / \mathrm{ml}$ em etanol a $-20^{\circ} \mathrm{C}$, onde os embriões permaneciam por 18 a 24 horas. Esta solução cora o DNA nuclear de todas as células. Findo este tempo, eles eram transferidos para lâminas em gotas de glicerina (Miyako do Brasil), cobertos com lamínulas e analisados em microscópio de fluorescência (Olympus - BX60) com filtro apropriado (Olympus - cubo U-MWU) e aumento de $100 \mathrm{X}$ e $400 \mathrm{X}$ para contagem do número total de células, que apresentavam o núcleo em fluorescência de cor azul (Figura 3).

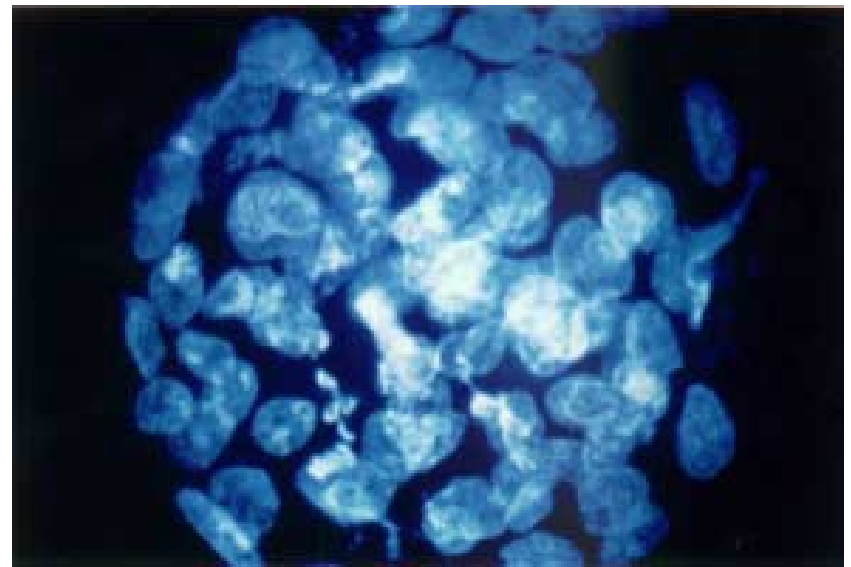

Figura 3 - Blastocisto corado pela técnica de coloração de Hoescht, no dia 8 pósfertilização in vitro (400 X).

A variável contagem de células foi representada por média, desvio padrão (DP), mediana e valores mínimo e máximo. Em razão da grande variabilidade (desvio padrão grande), foi utilizada a prova não-paramétrica de Mann-Whitney (U) para amostras independentes. A variável evolução do embrião para blastocisto e para o fenômeno de extrusão da zona pelúcida pelo blastocisto ("hatching") foi representada por freqüência absoluta (n) e relativa (\%) em tabela de dupla entrada. Foi aplicado o teste do $\chi^{2}$ para verificar a existência de associação na evolução entre os grupos dos embriões. Adotou-se o nível de significância de 0.05 ( $\alpha=5 \%$ ). Niveis descritivos (p) inferiores a esse valor foram considerados significantes. 


\section{Resultados}

Foram retirados 215 ovários de vacas, recuperando-se destes 710 ovócitos viáveis que foram incluídos neste estudo. Destes foram obtidos 434 embriões $(61,1 \%)$, dos quais 114 ultrapassaram o estágio de 8 células $(26,3 \%)$ no dia 5 pós-inseminação e foram incluídos neste estudo, independentemente do seu grau morfológico. Os 320 embriões restantes, que não apresentaram número de células maior que 8 , foram desconsiderados do estudo.

Cinqüenta e sete embriões separados para este estudo foram biopsiados no dia 5 pósinseminação e mais 57 foram incluídos no grupo controle, que foi submetido às mesmas condições de cultura que o grupo dos embriões biopsiados. Em nenhuma das biópsias realizadas no estudo houve lesão destrutiva do embrião ou do blastômero removido, que inviabilizasse sua inclusão na análise.

O desenvolvimento dos embriões biopsiados e do grupo controle foi avaliado comparativamente. No grupo controle, 42 embriões desenvolveram-se até o estágio de blastocisto $(73,7 \%)$ até o dia 8 pósinseminação, e 40 embriões biopsiados alcançaram o mesmo estágio até o mesmo dia $(70,2 \%)$. Na Tabela 1 encontram-se os dados referentes à evolução dos embriões para blastocistos nos dois grupos estudados. O "hatching" ocorreu em 11 blastocistos $(27,5 \%)$ obtidos após biópsia e em 11 blastocistos (26,2\%) do grupo controle (Tabela 2).

Tabela 1 - Estudo comparativo da evolução dos embriões para blastocistos, entre 0 grupo controle e o grupo de embriões biopsiados.

\begin{tabular}{lcccc}
\hline Grupo & \multicolumn{2}{c}{ Controle } & \multicolumn{2}{c}{ Biopsiado } \\
\hline Evolução & $\mathbf{n}$ & $\%$ & $\mathbf{n}$ & $\%$ \\
Sim & 42 & 73,7 & 40 & 70,2 \\
Não & 15 & 26,3 & 17 & 29,8 \\
Total & 57 & 100,0 & 57 & 100,0 \\
\hline$\chi^{2}=0,04$ & $p=0,8349$ & & &
\end{tabular}

Tabela 2 - Estudo comparativo da evolução dos embriões para "hatching", entre 0 grupo controle e o grupo de embriões biopsiados.

\begin{tabular}{llclc}
\hline Grupo & \multicolumn{2}{c}{ Controle } & \multicolumn{2}{c}{ Biopsiados } \\
\hline Evolução & $\mathbf{n}$ & $\%$ & $\mathrm{n}$ & $\%$ \\
Sim & 11 & 26,2 & 11 & 27,5 \\
Não & 31 & 73,8 & 29 & 72,5 \\
Total & 42 & 100,0 & 40 & 100,0 \\
\hline
\end{tabular}

$\chi^{2}=0,001 \quad p=0,9080$

536

$\mathrm{RBCO}-\mathrm{v} .21, \mathrm{n}^{0} 9,1999$
A Tabela 3 mostra a distribuição do número de células dos embriões dos grupos biopsiados e nãobiopsiados (controle) após coloração de Hoescht. No grupo controle $24 \%$ dos embriões atingiram o estágio superior a 64 células, o mesmo ocorrendo com $26 \%$ controle e $23 \%$ dos biopsiados permaneceram no estágio entre 9-22 células (Figura 4).

Tabela 3 - Estudo comparativo da evolução dos embriões biopsiados e não biopsiados, por meio de contagem de células, no dia 8 pós-fertilização.

\begin{tabular}{lccccc}
\hline Grupo & Média \pm DP & Mediana & Mínimo & Máximo & $\mathbf{n}$ \\
\hline Controle & $39 \pm 21$ & 38 & 9 & 75 & 57 \\
Biopsiados & $38 \pm 22$ & 31 & 9 & 75 & 57 \\
\hline$U=1558,0$ & $p=0,7057$ & & & &
\end{tabular}

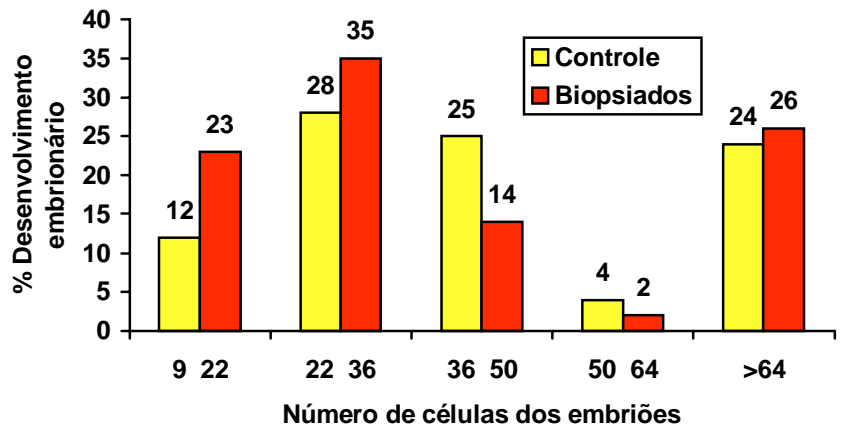

Figura 4 - Correlação entre o desenvolvimento embrionário dos embriões biopsiados e não-biopsiados, por meio da contagem de células no dia 8 pós-fertilização.

\section{Discussão}

Com o desenvolvimento de técnicas como hibridização in situ (FISH) e a reação em cadeia da polimerase (PCR), numa época em que se dominam as técnicas de reprodução humana, é possível a aplicação destas técnicas no diagnóstico pré-implantação. Para que possamos ter acesso ao diagnóstico pré-implantação, necessitamos de uma amostra dos gametas ou embriões em estudo, o que é possível por meio da biópsia. Porém, para uma boa aplicação deste diagnóstico, necessitase adotar uma técnica adequada para a biópsia.

A biópsia de blastômeros tem sido realizada por meio de diferentes técnicas: com a abertura da zona pelúcida usando solução ácida de Tyrode e introdução da micropipeta para aspiração dos blastômeros ${ }^{9}$; dissecação parcial da zona na qual uma micropipeta é passada através de uma área da zona pelúcida e com o auxílio da micropipeta de sustentação cria-se um abertura por onde a micropipeta de aspiração alcança o blastômero; ou dos biopsiados. Apenas 19\% dos embriões do grupo 
atravessa-se a zona pelúcida usando uma micropipeta biselada que remove o blastômero ${ }^{15}$. Ainda, pode-se remover o blastômero por meio da técnica de deslocamento, em que dois orifícios são necessários, sendo mantido em um dos orifícios um fluxo gentil de meio e no outro o blastômero é extrusado ${ }^{8}$.

Todas os métodos utilizados para biópsia necessitam de treinamento, pois todos oferecem dificuldades como perdas de blastômeros e embriões e imprecisão na interpretação dos resultados dos exames. Existem muitas controvérsias entre os autores quanto à melhor técnica para a biópsia de blastômeros. A técnica adotada deve manter o blastômero removido intacto para que não haja perda de material genético e danificar o mínimo possivel o embrião, de maneira que ele continue viável. A utilização de solução ácida de Tyrode na confecção do orifício, no qual deve ser introduzida a pipeta de aspiração, pode causar danos aos embriões devido à acidez do $\mathrm{pH}$, caso quem esteja manipulando não tenha bastante prática e rapidez. A utilização de pipeta biselada para ultrapassar a zona pelúcida pode danificar alguns blastômeros durante a introdução da pipeta. Neste estudo nós utilizamos um método mecânico na tentativa de minimizar estes problemas.

Para que possamos realizar estes procedimentos com destreza, necessitamos de um protocolo de treinamento que nos possibilite a aquisição de experiência e aprimoramento de técnica manual. Para treinamento utilizam-se com freqüência embriões de camundongo, necessitando de manutenção de biotério e o cruzamento entre duas raças específicas, o que dificulta o procedimento. Já é possivel a obtenção de embriões de camundongos ${ }^{7,8}$ congelados, em empresas especializadas, em outros países, evitando-se desta maneira a necessidade de biotério. Porém, esta importação torna-se inviável, quando levamos em conta seus altos custos, e consideramos as perdas que ocorrem normalmente durante o transporte e no descongelamento.

Em contraste, os embriões bovinos podem ser conseguidos por meio de oócitos de vacas de abatedouros locais e o sêmen pode ser obtido facilmente no comércio. Apesar de os vários protocolos de treinamento e experimentação com a utilização de animais serem valiosos e demonstrarem ser eficazes, acreditamos serem de alto custo e de difícil acesso à maioria dos profissionais. Nosso protocolo é muito barato, já que dispensa a necessidade de um biotério e todo trabalho que ele representa. Utilizamos bovinos, animal de fácil aquisição em qualquer parte do país, possibilitando a maturação in vitro dos gametas e também possibilitando que se acompanhe o fenômeno da fertilização e do desenvolvimento embrionário. A utilização de embriões bovinos para a biópsia oferece também a possibilidade de treinamento em fertilização in vitro, o que não acontece quando se trabalha com embriões de camundongo, cuja fertilização ocorre in vivo.

$\mathrm{O}$ acesso a grande número de gametas e embriões em um período muito curto possibilita treinamento em curto espaço de tempo, e acreditamos que o profissional que manipula com perícia os embriões bovinos esteja apto a manusear embriões humanos, além de ter a sua disposição um modelo de aprimoramento de novas técnicas que surgem continuamente, como as recentes técnicas de abertura da zona pelúcida com laser e o transplante de citoplasma e núcleo. Para comprovar a eficácia desta proposta, os embriões biopsiados sempre foram comparados a um grupo controle que era submetido às mesmas condições de cultura.

Comparando os resultados obtidos entre embriões biopsiados com os não-biopsiados, observou-se que não houve diferença estatisticamente significante entre os dois grupos em relação à evolução para blastocisto ou "hatching". A avaliação pela contagem de células, com o auxílio de coloração específica para núcleos, também confirmou que não houve diferença estatisticamente significante entre os dois grupos estudados. Assim, nossos resultados comprovam que o protocolo proposto é viável.

\section{SUMMARY}

Purpose: to develop an animal model for the study of, and training in, bovine biopsies.

Methods: cow ovaries were obtained from a slaughterhouse and transported to the laboratory where the oocytes were aspirated, maturated and submitted to in vitro fertilization. On the 5th day after fertilization, the embryos were biopsied, with the zona pellucida being opened with a cutting blade fitted to the light microscope. One or two blastomeres were removed from the embryos and left in coculture for three additional days. After this time, embryo development was evaluated in comparison to a control group by morphological study and cell counts using specific staining for nuclei.

Results: forty of the 57 biopsied embryos reached the blastocyst stage (70.2\%) and hatching was observed in 11 (27.5\%). Forty-two blastocysts were obtained in the control group $(73.7 \%)$ and 11 of them hatched $(26.2 \%)$. Cell counts showed no significant differences between groups. 
Conclusions: we conclude that the proposed protocol is technically feasible and supplies a good number of embryos because of the easy technique for obtaining bovine oocytes, thus representing a method that could be adopted for training.

KEY WORDS: Infertility. Cell culture. In vitro fertilization.

\section{Referências}

1. Ekelund H, Kullander S, Källen B. Major and minor malformation in newborns and infants up to one year of age. Acta Paediatr Scand 1970; 59:297-302.

2. Steele MV, Breg WR. Chromosome analysis of human amniotic-fluid cells. Lancet 1966; 1:383-5.

3. Valenti C, Schutta EJ, Kehaty T. Prenatal diagnosis of Down`s Syndrome. Lancet 1968; 2:220-4.

4. Verlinsk Y, Kuliev AM, editores. Preimplantation Diagnosis of Genetic Diseases. New York: Willey-Liss; 1991. p. 1-2.

5. Gardner RL, Edwards RG. Control of the sex ratio at full term in the rabbit by transferring sexed blastocysts. Nature 1968; 218:346-9.

6. Summers PM, Campbell JM, Miller MW. Normal invivo development of marmoset monkey embryos after trophectoderm biopsy. Hum Reprod 1988; 3:389-93.

7. Nijs M, Van Steirteghem AC. Assessment of different isolation procedures for blastomeres from twocell mouse embryos. Hum Reprod 1987; 2:421-4.
8. Roudebush WE, Kim JG, Minhas BS, Dobson MG. Survival and cell acquisition rates after preimplantation embryo biopsy: use of two mechanical techniques and two mouse strains. Am J Obstet Gynecol 1990; 162:1084-90.

9. Handyside AH, Kontogianni EH, Hardy K, Winston RML. Pregnancies from biopsied human preimplantation embryos sexed by Y-specific DNA amplification. Nature 1990; 344: 768-70.

10.Hardy K, Martin KL, Leese HJ, Winston RML, Handyside AH. Human preimplantation development in vitro is not adversely affected by biopsy at the 8-cell stage. Hum Reprod 1990; 5: 708-14.

11.Pavlock A. In vitro tecchniques of bovine oocyte maturation, fertilization and embryo culture resulting in the bird of a calf. Reprod Nutr Develop 1989; 25:611-6.

12.Parrish JJ, Susko-Parrish JL, Liebfried-Rutledge ML, Crister ES, Eyestone WK, First NL. Bovine in vitro fetilization with frozen-thawed semen. Theregenology 1986; 25:591-600.

13.Bavister BD, Yanagimack R. The effects of sperm extracts and energy source on the motility and acrosome reaction of hamster spermatozoa invitro. Biol Reprod 1977; 16:228 - 37.

14.Papaioannou VE, Ebert KM. The preimplantation pig embryos: cell and allocation trophectoderm and inner cell mass of the blastocist in vivo and in vitro development. Development 1988; 102: 793803.

15.Depypere HT, Leybaert L, Dhont M, De Hemptinne A, Vandekerckhove D. The intracytoplasmatic $\mathrm{pH}$ change during zona drilling of mouse oocytes. Hum Reprod 1990; 5 (Suppl): 6-7.

\section{RBGO}

\section{éumapublicação da FEBRASOO}

\section{equeaceitaartigosprovenientesdeginecologistas,} obstetrasedeoutrasespecialidades. Portanto, publique!!! 